Mens

revue d'histoire intellectuelle de l'Amérique française

\title{
Urgence de la poésie philosophique
}

\section{Benoît Lacroix}

Volume 4, numéro 1, automne 2003

URI : https://id.erudit.org/iderudit/1024629ar

DOI : https://doi.org/10.7202/1024629ar

Aller au sommaire du numéro

Éditeur(s)

Centre de recherche en civilisation canadienne-française

ISSN

1492-8647 (imprimé)

1927-9299 (numérique)

Découvrir la revue

Citer cette note

Lacroix, B. (2003). Urgence de la poésie philosophique. Mens, 4(1), 95-97.

https://doi.org/10.7202/1024629ar d'utilisation que vous pouvez consulter en ligne.

https://apropos.erudit.org/fr/usagers/politique-dutilisation/ 


\title{
URGENCES DE LA POÉSIE PHILOSOPHIQUE
}

\author{
Benoît Lacroix
}

La poésie n'en finit plus de protéger le mystère et souvent elle le garde mieux que tous les énoncés dogmatiques. Elle habite aux frontières de l'invisible et de l'infini. Sa nature est non de dissimuler mais bien de voiler. Il arrive au Québec depuis quelques décennies que nos poètes vont dans toutes les directions, depuis la tendance plus facile d'une poésie à fleur de peau jusqu'aux poèmes nettement spiritualistes d'une Rina Lasnier ( 1997) et, tout récemment, de Jean-Marc Fréchette, de Jacques Gauthier, et d'autres.

Il existe aussi, plus rares, des poètes conduits par l'interrogation philosophique. Pour en savoir davantage sur les tendances de cette poésie métaverbale, il convient peut-être de relire les propos tenus jadis par nul autre que Jacques Brault dans Urgences de la philosophie (pp. 348-356) et que l'on peut relire dans Poussière du chemin (pp. 216-229). Le texte est savamment intitulé "Sagesse de la poésie ».

On retrouve un exemple plus récent de cette poésie toute en sagesse et interrogations philosophiques dans l'anthologie D'argile et de souffle, choix de poèmes de Hélène Dorion, présentés et préparés avec goût et pertinence par Pierre Nepveu. En fait, qui un jour ou l'autre s'aventure à relire les présocratiques, Platon et, dans le cas de Dorion, Plotin, trou- 
vera dans l'anthologie Dorion des mots sérieux, savamment choisis, des textes méditatifs sur les mêmes et éternelles expériences du temps, de l'instant, de la durée, du temps en lien avec l'éternité, et sur la divinité, le fini et l'infini. L'auteure ici est d'une lucidité doucement incisive. Des mots, des images, un style, qui inspirent le silence. Nostalgie des recommencements : "La mémoire ne sait pas où se poser... Seul avec l'immensité, l'enfant traverse le sombre désordre du monde. » Cet enfant, on s'en doute, est lucide et clairvoyant. Il veut recommencer l'histoire. Il n'en finit plus d'interroger le temps, celui qui passe inexorablement ou celui qui le blesse. «Voici le temps, mon âme. Retourne-le sans hâte... » Chaque jour arrive en désir d'éternité. Comment échapper à l'infini qui nous hante? «Nous avançons encore, portés par l'infini. »

En fait, il n'y a qu'une lecture rythmée et lente des poèmes de madame Dorion qui puisse rendre justice à ses textes et par eux à ce que nous avons appelé la poésie philosophique. La publication plus récente par la même auteure de Jours de Sable (2002) offre une aide supplémentaire à toute personne en quête de sagesse existentielle. Mieux, l'intérêt croissant de notre philosophe et poète pour les platoniciens, pour Plotin (III ${ }^{e}$ siècle) et ses Ennéades, vient d'être généreusement confirmé dans Le Silence (2002). Il s'agit d'une traduction en collaboration avec l'auteur d'une œuvre poétique du poète catalan, Carles Duarte i Montserrat, où nous retrouvons une autre fois Plotin, source évidente d'une inspiration noblement partagée.

Le moment est-il propice de saluer à l'occasion de la parution D'argile et de souffle le courage non moins exemplaire de ces compagnies théâtrales de Montréal qui osent encore nous présenter les œuvres des Anciens, telles Oreste, OEdipe roi, Antigone, Les Troyennes, etc. L'histoire de la culture con- 
firme que chaque retour à l'antiquité grecque, que Hélène Dorion appellerait sans doute la "sagesse des recommencements ", amorce à sa manière une renaissance. Héraclite, l'énigmatique Héraclite depuis très longtemps déjà scrutant tout ce qui s'appelle âme, être, pensée, divin, en conclut sagement à quel point il est important de vivre parfois en retrait, de prendre ses distances vis-à-vis des voix discordantes de la réflexion populaire, pour mieux réentendre la rumeur des sagesses anciennes : «De tant de paroles écoutées, aucune n’est arrivée à la connaissance : ce qui est sage est séparé de toutes. » 